features include Smith-Lemli-Opitz, Zellweger, and glutaric acidemia type II (see Menkes JH. In: Progress in Pediatric Neurology III, Millichap JG, ed. Chicago, PNB Publishers, 1997; pp533-535).

\title{
PENICILLAMINE-INDUCED SIGNS OF WILSON DISEASE
}

A 9-year-old boy with asymptomatic Wilson disease who developed neurologic symptoms after treatment with penicillamine is reported from the Department of Pediatrics, Universita Federico II, Naples, Italy. Initially referred for isolated hypertransaminasemia, and hepatomegaly was the only sign of Wilson disease. The diagnosis was confirmed with abnormal urinary copper excretion and high liver copper. After 10 weeks of treatment with penicillamine $(20 \mathrm{mg} / \mathrm{kg} / \mathrm{day})$ and pyridoxine $(25 \mathrm{mg} /$ day $)$, the child developed a tremor of the upper limbs which became progressively severe and incapacitating. Zinc sulfate (100 mg 3x daily) therapy and omission of penicillamine were followed by marked improvement within 2 weeks and remission of tremor at 4 month and 30-month follow-up. Serum transaminase and urinary copper levels were decreased following zinc treatment. (Porzio S, Iorio R, Vajro P, Pensati P, Vegnente A. Penicillamine-related neurologic syndrome in a child affected by Wilson disease with hepatic presentation. Arch Neurol Sept 1997;54:1166-1168). (Reprints: Salvatore Porzio MD, Dipartimento di Pediatria, Universita "Federico II," via S Pansini 5, 80131 Napoli, Italia).

COMMENT. Penicillamine therapy for Wilson disease may rarely precipitate the onset of neurologic symptoms. The authors cite only 5 previous cases, all adults. Zinc appears to be a satisfactory alternative treatment in a limited series. Other reported side-effects of penicillamine include fever, rash, adenopathy, pyridoxine-responsive optic neuritis, nephrotic syndrome, thrombocytopenia, and leukopenia. (Menkes JH. Textbook of Child Neurology, 3rd ed, Philadelphia, Lea \& Febiger, 1985; p93).

\section{HEREDO-DEGENERATIVE DISEASES}

\section{PELIZAEUS-MERZBACHER-LIKE DISEASE}

A family with X-linked inheritance and Pelizaeus-Merzbacher-like disease (PMLD), PMD without the proteolipid protein (PLP) mutation, studied at the UMDNJ-Robert Wood Johnson Medicial School, New Brunswick, NJ, had a new locus on Xq chromosome, more than $10 \mathrm{cM}$ away from PLP. A clinical diagnosis of PMD in the proband was made on the X-linked inheritance, congenital onset, nystagmus, slow progression with pyramidal signs, seizures, and psychomotor deterioration. The patient died at 25 years, and neuropathological study showed calcific vasculopathy in the basal ganglia and dentate nucleus and intact myelin. (Lazzarini A, Schwarz KO, Jiang S, Stenroos ES, Lehner T, Johnson WG. Pelizaeus-Merzbacher-like disease: Exclusion of the proteolipid protein locus and documentation of a new locus on Xq. Neurology Sept 1997;49:824-832). (Reprints: Dr Alice Lazzarini, Department of Neurology, UMDNJRobert Wood Johnson Medical School, 97 Paterson St, New Brunswick, NJ 08903).

COMMENT. PMD patients having mutations in the PLP gene have an onset of symptoms in early infancy, nystagmus, spastic diplegia, ataxia, titubation, head bobbing, hypotonia, and mental retardation. Classical type I PMD has 'tigroid' or perivascular preserved myelin and a life span up to 25 years, whereas type II PMD has diffuse demyelination and death before 10 
years of age. The above report identifies a kindred with PM-Like D, clinically resembling PMD, but with intact myelin and with mutations at a new locus on the $\mathrm{X}$ chromosome.

\section{SPINAL MUSCULAR ATROPHY AND ARTHROGRYPOSIS}

Four infants with neurogenic arthrogryposis who died of respiratory failure before 1 month of age had DNA testing of autopsy specimens for $S M N^{T}$ gene deletion in a study at the Children's Hospital of Philadelphia, PA, and the Children's Hospital at Dartmouth, Lebanon, NH. All infants had clinical, pathologic, or EMG evidence of motor neuron disease. In addition to anterior horn cell loss, autopsies showed a more extensive neurodegeneration involving central sensory neurons in Clarke's column and the thalamus. $S M N^{T}$ deletion was identified in two of the cases. (Bingham PM, Shen N, Rennert H et al. Arthrogryposis due to infantile neuronal degeneration associated with deletion of the $S M N^{T}$ gene. Neurology Sept 1997;49:848-851). (Reprints: Dr PM Bingham, Division of Child Neurology, Children's Hospital of Philadelphia, Philadelphia, PA 19104).

COMMENT. Arthrogryposis in association with infantile spinal muscular atrophy (Werdnig-Hoffmann disease) was first reported by Byers and Banker (1961). DNA analysis for $S M N^{T}$ deletion in cases of neurogenic arthrogryposis may uncover a diagnosis of spinal muscular atrophy or SMA variant and facilitate genetic counselling. Some cases of infantile SMA may have degenerative changes in sensory neurons in addition to the classical anterior horn cell loss.

Congenital axonal neuropathy with $S M N$ deletion is reported in three newborn siblings presenting with generalized weakness, asphyxia, facial diplegia, and external ophthalmoplegia, and studied at Pediatric University Hospital, Mathildenstr, Freiburg, Germany (Korinthenberg R, Sauer M, Ketelsen U-P et al. Ann NeurolSept 1997;42:364-368). EMG, NCV, and nerve biopsies confirmed an axonal neuropathy. The electrophysiological and biopsy findings, together with the $S M N$ gene deletion, were diagnostic of a severe spinal muscular atrophy, complicated by involvement of brainstem nuclei and sensory nerves. Contrary to accepted criteria, weakness of extraocular muscles and facial weakness do not exclude the diagnosis of SMA.

\section{VASCULAR DISORDERS}

\section{FACTOR V LEIDEN MUTATION AND NEONATAL STROKE}

Three infants with familial factor $V$ Leiden mutation and neonatal cerebrovascular disorders are reported from the Children's Hospital of Philadelphia, PA. One had placental thrombosis. Activated protein $\mathrm{C}$ resistance caused by factor $\mathrm{V}$ Leiden mutation is an important cause of in utero ischemic infarction and hemorrhagic stroke and may present with neonatal hemiplegic cerebral palsy. (Thorarensen O, Ryan S, Hunter J, Younkin DP. Factor V Leiden mutation: an unrecognized cause of hemiplegic cerebral palsy, neonatal stroke, and placental thrombosis. Ann Neurol Sept 1997;42:372-375). (Dr Younkin, Division of Neurology, 6th Floor, Wood Bldg, Children's Hospital of Philadelphia, 34th St and Civic Center Blvd, Philadelphia, PA 19104).

COMMENT. Infants with hemiplegic cerebral palsy caused by a vascular accident should be tested for factor $\mathrm{V}$ Leiden mutation, especially if a parent 